\title{
SOME NEW FEATURES IN THE DECAY OF ${ }^{142} \mathrm{Pr}$ \\ JOHN C. HILL and M. L. WIEDENBECK \\ Department of Physics, University of Michigan, Ann Arbor, Michigan ${ }^{\dagger}$
}

\author{
Received 8 March 1968
}

\begin{abstract}
T$ he ${ }^{142} \mathrm{Pr} \rightarrow{ }^{142} \mathrm{Nd}$ decay was investigated, and a new gamma ray at $508 \mathrm{keV}$ was found depopulating a level at $2084 \mathrm{keV}$. On the basis of energy, intensity and coincidence measurements using a $\mathrm{Ge}(\mathrm{Li})$ detector, a new decay scheme is proposed. The new level is probably identical to a $3^{-}$level seen in reaction studies.
\end{abstract}

\section{Introduction}

The decay of ${ }^{142} \mathrm{Pr}$ to levels in ${ }^{142} \mathrm{Nd}$ has been studied by several investigators ${ }^{1-4}$ ), but only one gamma transition has been observed. The levels of ${ }^{142} \mathrm{Nd}$ have also been investigated through nuclear reactions ${ }^{5-8}$ ). Levels at 1970 and $2090 \mathrm{keV}$ have been proposed ${ }^{9}$ ) which are below the beta $Q$-value of $2163.2 \pm 1.8 \mathrm{keV}$. As part of a program to investigate the level structure of the $N=82$ isotones, we have restudied the decay of ${ }^{142} \mathrm{Pr}$ in order to observe gamma de-excitation from the above levels.

\section{Source preparation}

Several $\mathrm{mg}$ of $\operatorname{Pr}_{2} \mathrm{O}_{3}$ were irradiated in the thermal neutron flux of The University of Michigan Ford Reactor for about $24 \mathrm{~h}$. The praseodymium was chemically separated from all other elements using the procedure of Stevenson and Nervik ${ }^{10}$ ). The $\mathrm{pH}$ of the $1 M$ lactic acid elutant used in the rare-earth separation was 3.8. No interfering activities were observed in sources less than $3 \mathrm{~d}$ old.

\section{Gamma-ray energies and intensities}

The gamma spectrum was observed with a $17 \mathrm{~cm}^{3}$ coaxial lithium-drifted germanium spectrometer. The resolution (fwhm) for the $662 \mathrm{keV}$ gamma ray of ${ }^{137} \mathrm{Cs}$ was $3.1 \mathrm{keV}$. A typical gamma spectrum for ${ }^{142} \mathrm{Pr}$ is shown in fig. 1. The peak at about $509 \mathrm{keV}$ is shown in detail in the inset in fig. 1. It consists of a new gamma ray at $508 \mathrm{keV}$ plus annihilation radiation. The intensity of the composite peak was

$\dagger$ Work supported in part by U.S. Atomic Energy Commission. 
monitored for three half-lives in order to unambiguously identify it with ${ }^{142} \mathrm{Pr}$ decay. In spectra of mixed sources of ${ }^{142} \mathrm{Pr}$ and ${ }^{22} \mathrm{Na}$, a shift of the $509 \mathrm{keV}$ peak to the high-energy side was observed further verifying the composite nature of the peak.

The energies and errors of all gamma rays were determined as in earlier work ${ }^{11}$ ) using standard gamma rays from ${ }^{7} \mathrm{Be},{ }^{137} \mathrm{Cs},{ }^{54} \mathrm{Mn},{ }^{60} \mathrm{Co}$ and ${ }^{88} \mathrm{Y}$ [ref. $\left.{ }^{12}\right)$ ]. The

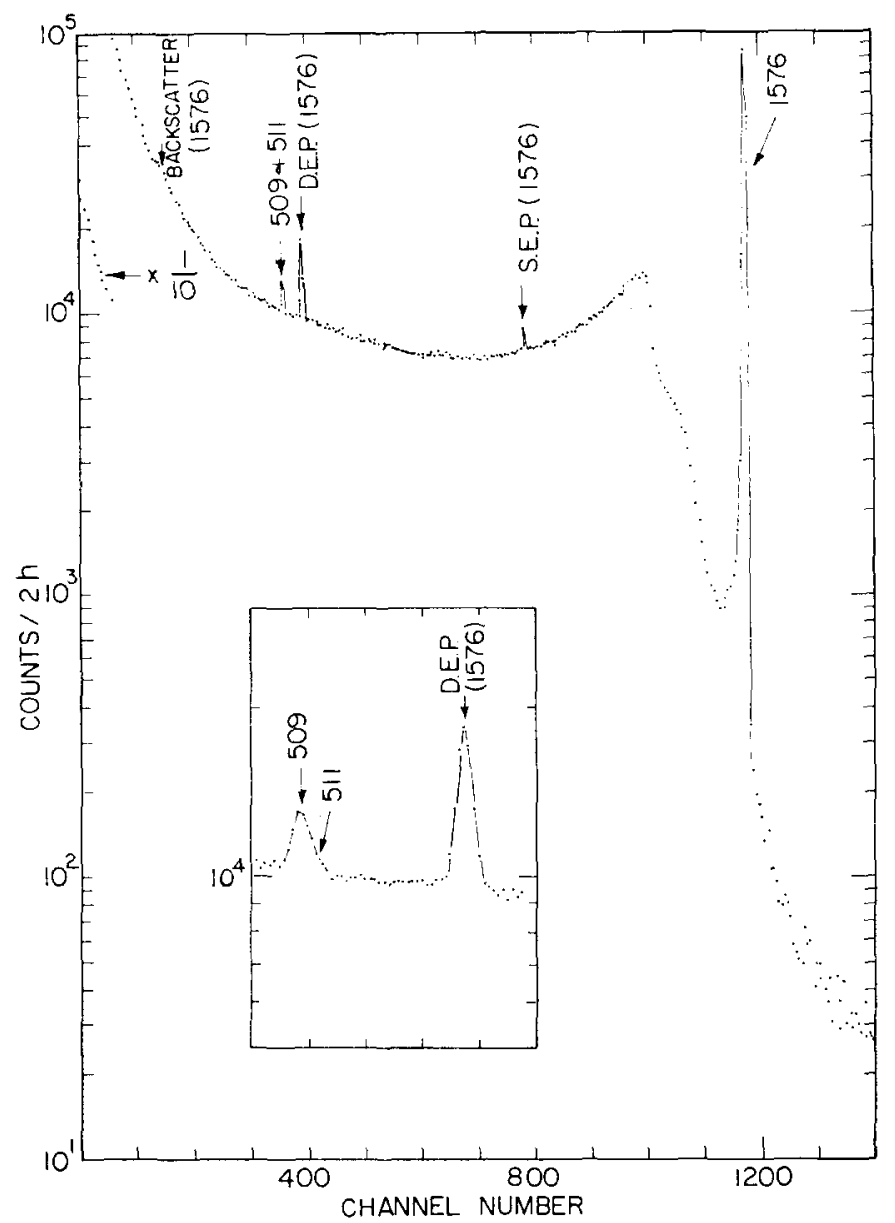

Fig. 1. The pulse-height spectrum of gamma radiation accompanying the decay of ${ }^{142} \mathrm{Pr}$. The source distance to the $17 \mathrm{~cm}^{3}$ coaxial $\mathrm{Ge}(\mathrm{Li})$ detector was $5 \mathrm{~cm}$. No absorber was used; S.E.P. and D.E.P. represent single and double escape peak, respectively. All energies are in keV.

energy of the gamma ray depopulating the first excited state was determined to be $1575.9 \pm 0.2 \mathrm{keV}$ in agreement with the value of $1575.4 \pm 0.4 \mathrm{keV}$ measured with the curved-crystal spectrometer at this laboratory by Baer ${ }^{13}$ ). A value of $508.1 \pm 0.8 \mathrm{keV}$ was obtained for the low-energy gamma ray. The large error represents uncertainty in unfolding the 508 and $511 \mathrm{keV}$ gamma rays. 
The intensity of the $508 \mathrm{keV}$ gamma ray was found to be $0.67 \pm 0.3$ relative to an intensity of 100 for the $1576 \mathrm{keV}$ gamma ray. Methods from earlier work ${ }^{11}$ ) were used. Most of the error resulted from uncertainty in peeling apart the composite peak. A search was made for gamma transitions to the ground state depopulating levels at 1970 and $2084 \mathrm{keV}$. An upper limit of 0.06 was placed on the intensity of each transition.

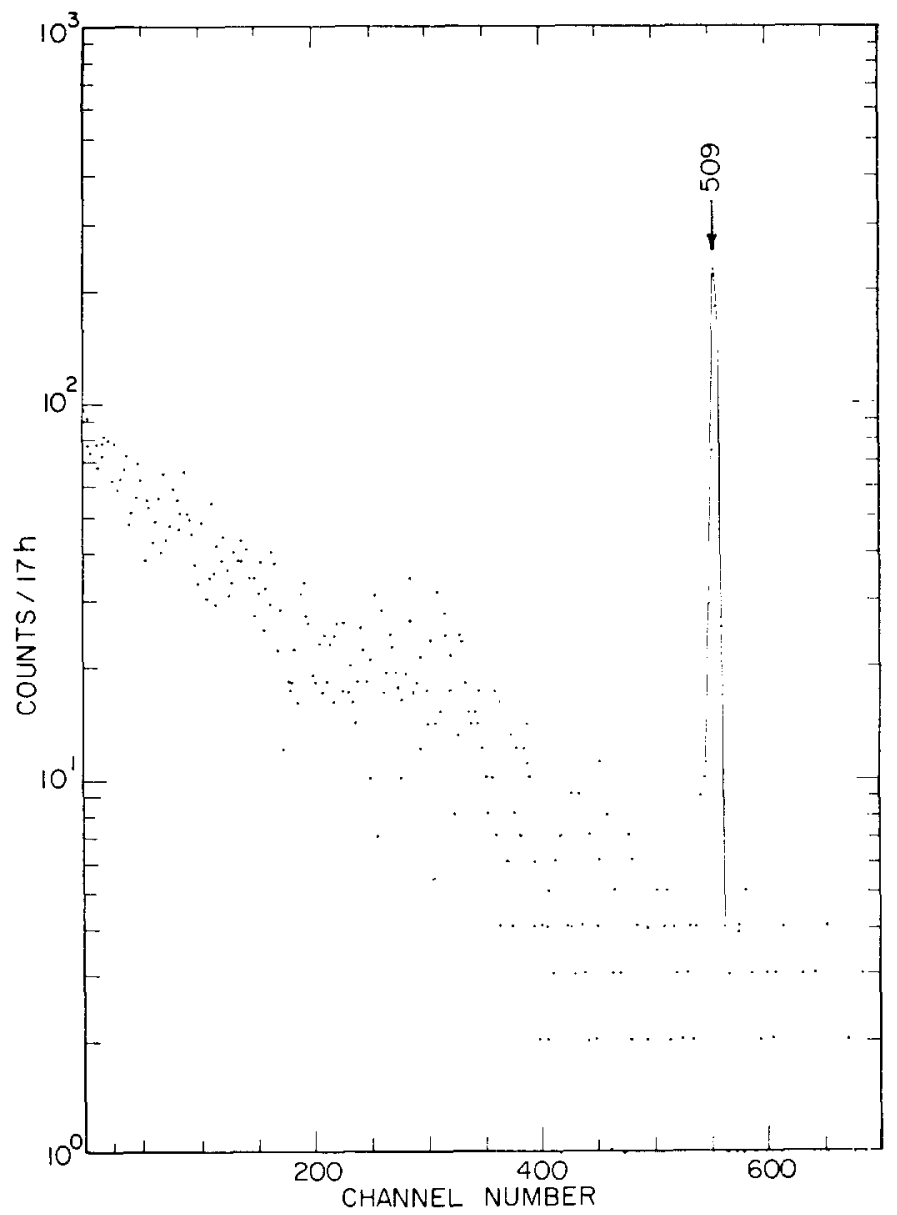

Fig. 2. The pulse-height spectrum of gamma radiation in coincidence with the $1576 \mathrm{keV}$ gamma ray. All energies are in keV.

\section{Gamma-gamma coincidence measurements}

Gamma-gamma coincidence studies were carried out using a $7.6 \mathrm{~cm} \times 7.6 \mathrm{~cm}$ $\mathrm{NaI}(\mathrm{Tl})$ detector and the $\mathrm{Ge}(\mathrm{Li})$ detector. The coincidence resolving time was about 50 nsec. The spectrum observed in coincidence with the $1576 \mathrm{keV}$ gamma ray is shown in fig. 2. The multi-channel analyser was gated from the NaI spectrometer and 
a true-to-chance ratio of 2 was used. The spectrum is corrected only for chance coincidences.

Coincidences were observed only with the $508 \mathrm{keV}$ gamma ray. Comparison with a single spectrum taken under identical conditions proved that the coincidence peak originated from the $508 \mathrm{keV}$ gamma ray and not annihilation radiation. A search was made for gamma rays depopulating a level at $1970 \mathrm{keV}$. From our coincidence data, an upper limit of 0.05 was placed on decay from the above level to the $1576 \mathrm{keV}$ level.

\section{Decay scheme and discussion}

The decay scheme based on the results of this investigation is shown in fig. 3 . The energy of the first excited state was determined to be $1575.9 \pm 0.2 \mathrm{keV}$ in disagreement with the value of $1572 \mathrm{keV}$ recently accepted by the nuclear data group ${ }^{9}$ ).

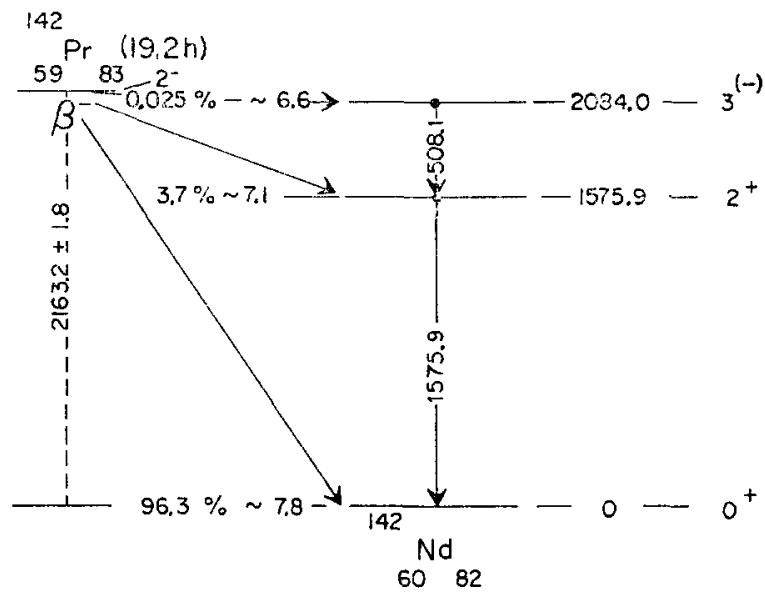

Fig. 3. The decay scheme of ${ }^{142} \mathrm{Pr}$ from the present studies.

A new gamma ray at $508 \mathrm{keV}$ was observed in coincidence with the gamma ray at 1576 $\mathrm{keV}$. We thus propose a new level with an energy of $2084.0 \pm 0.9 \mathrm{keV}$. No evidence was seen for population of a level at $1970 \mathrm{keV}$ observed in (d, $\left.d^{\prime}\right)$ scattering ${ }^{7}$ ). The relative intensity of beta rays feeding the ground and first excited states was obtained from the work of Langhoff et al. ${ }^{4}$ ). The $\log f t$ assignment for the $2084 \mathrm{keV}$ level was calculated from our intensity measurements and found to be 6.6. A lower limit for the $\log f t$ of beta decay to the $1970 \mathrm{keV}$ level was determined to be 8.8 .

The assignment of the $1576 \mathrm{keV}$ level is shown to be $2^{+}$from Coulomb excitation ${ }^{8}$ ), and the assignment of the ${ }^{142} \mathrm{Pr}$ ground state is known to be $2^{-}$from a direct spin measurement ${ }^{14}$ ) and the first-forbidden unique character ${ }^{2}$ ) of the beta transition feeding the ${ }^{142} \mathrm{Nd}$ ground state. The spin of the $2084 \mathrm{keV}$ level is thus limited to 1,2 or 3 . The absence of a transition from this level to the ground state favors a spin of 3 , 
and the low $\log f t$ value weakly favors a negative parity. Our $2084 \mathrm{keV}$ level is probbably identical to the $3^{-}$level observed in $\left(\alpha, \alpha^{\prime}\right)$ [ref. $\left.{ }^{5}\right)$ ] and (d, $\left.\mathrm{d}^{\prime}\right)$ [ref. $\left.{ }^{7}\right)$ ] scattering and a level observed by Krehbiel $^{6}$ ) in the decay of a $16.5 \mu \mathrm{sec}$ isomeric state in ${ }^{142} \mathrm{Nd}$. The energy of the gamma ray seen by Krehbiel was $525 \mathrm{keV}$ in comparison with our value of $508 \mathrm{keV}$. The possibility thus exists that our state at $2084 \mathrm{keV}$ is not the same as the one seen by Krehbiel ${ }^{6}$ ).

The authors wish to thank Professor J. J. Reidy for help during the course of the experiments.

\section{References}

1) E. N. Jensen, L. J. Laslett and D. J. Zaffarano, Phys. Rev. 80 (1950) 862

2) A. V. Pohm, W. E. Lewis, J. H. Talboy and E. N. Jensen, Phys. Rev. 95 (1954) 1523

3) E. Freiberg and K. Goebel, Z. Naturf. 14a (1959) 679

4) H. Langhoff, P. Kilian and A. Flammersfeld, Z. Phys. 165 (1961) 387

5) O. Hansen and O. Nathan, Nucl. Phys. 42 (1963) 197

6) H. Krehbiel, Phys. Lett. 13 (1964) 65

7) P. R. Christensen and F. C. Yang, Nucl. Phys. 72 (1965) 657

8) D. Eccleshall, M. J. L. Yates and J. J. Simpson, Nucl. Phys. 78 (1966) 481

9) S. Raman, Nuclear Data Sheets for $A=142$, Nuclear Data B2-1-1 (1967)

10) P. C. Stevenson and W. E. Nervik, U. S. Atomic Energy Commission Report No. NAS-NS-3020 (1961)

11) John C. Hill and M. L. Wiedenbeck, Nucl. Phys. A98 (1967) 599

12) C. M. Lederer, J. M. Hollander and I. Perlman, Table of isotopes (John Wiley and Sons, New York, 1967) p. 561

13) H. W. Baer, private communication

14) A. Cabezas, I. Lindgren, R. Marrus and W. Nierenberg, Phys. Rev. 126 (1962) 1004 